\title{
pretiles elásticos para carreteras
}

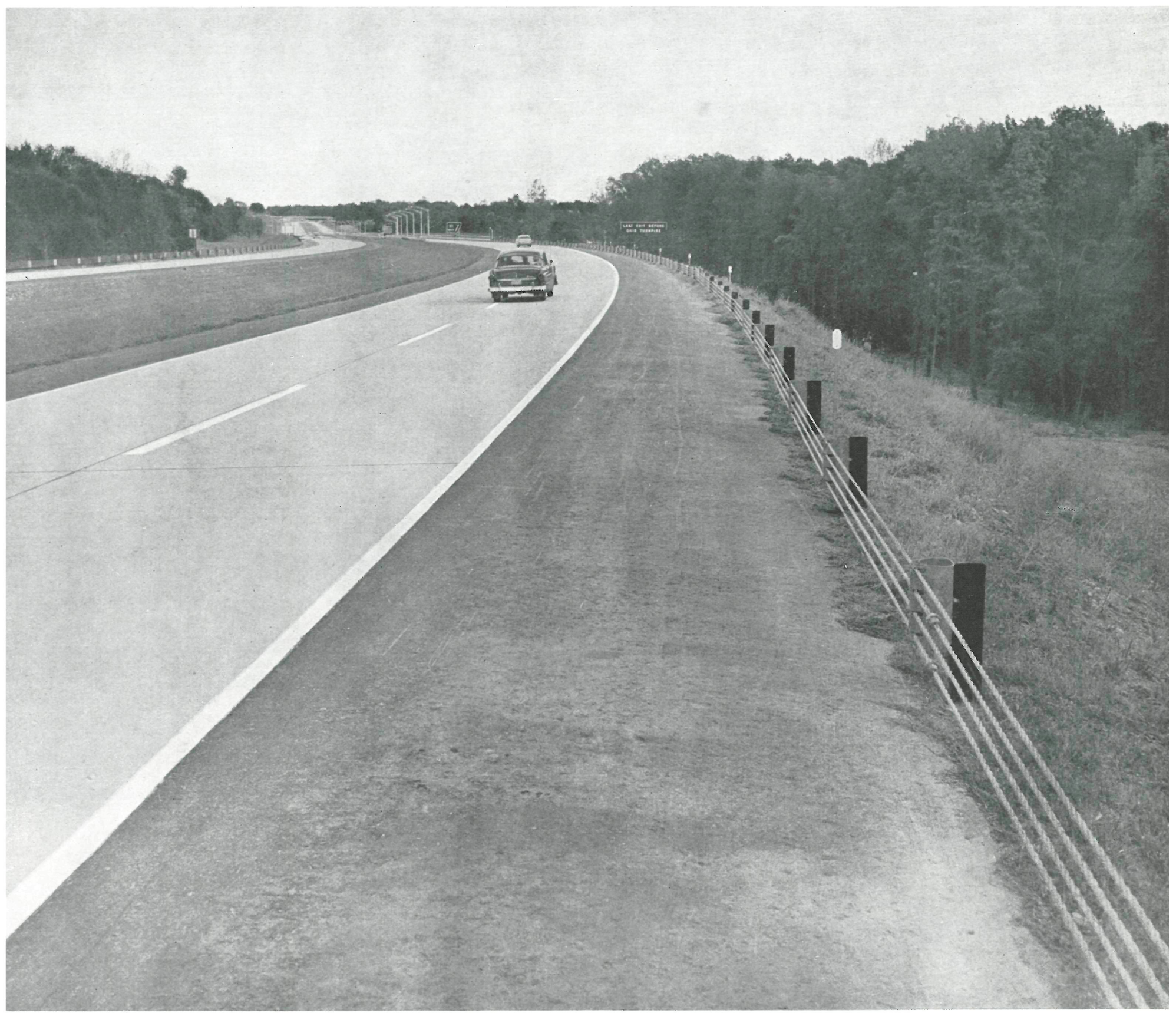

$516 \cdot 1$

S I I N $\begin{array}{llllllllll} & \text { O } & \text { I } & S\end{array}$

Para proteger los vehículos que circulan en las carreteras de una posible salida lateral en la misma por un despiste o accidente, la American Steel \& Wire fabrica un tipo de pretil elástico, utilizando cables, que está dando resultados satisfactorios, y del que damos una ligera descripción en este trabajo. 


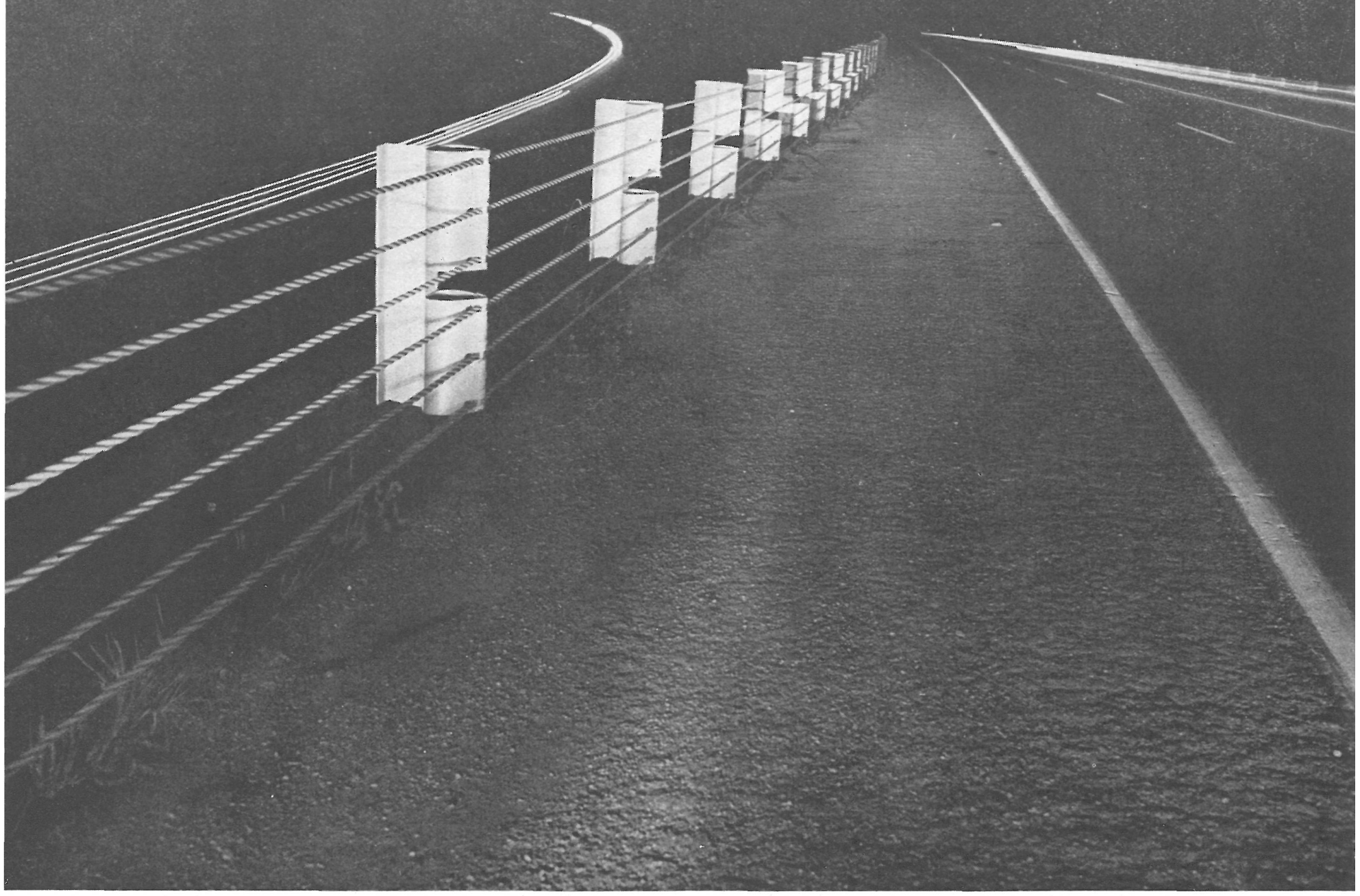

Fotos: HENRY M. BARR

\section{Generalidades}

Aunque los trazados de carreteras se han adaptado rápidamente a las exigencias y seguridad de la circulación por las mismas, los despistes y accidentes son causas que han de preverse, no sólo en los puentes y curvas más o menos peligrosas, sino en los propios tramos rectos, ya que, de ocurrir el accidente, una de las tendencias del vehículo es la de salir despedido de la calzada.

Actualmente, es una práctica muy generalizada la de aislar, en la medida de lo posible, la banda que constituye el camino del resto que le rodea, utilizando para ello distintos medios y procedimientos. El principio de esta orientación tiene un significado profundamente práctico y racional, ya que, aparte los accidentes propios de la circulación, debidos a falsas maniobras entre los usuarios de la carretera, muchas veces el origen del accidente hay que buscarlo fuera del camino, es decir, en peatones, ganado y cruces inesperados o impropia utilización de espaldones. 


\section{planta}

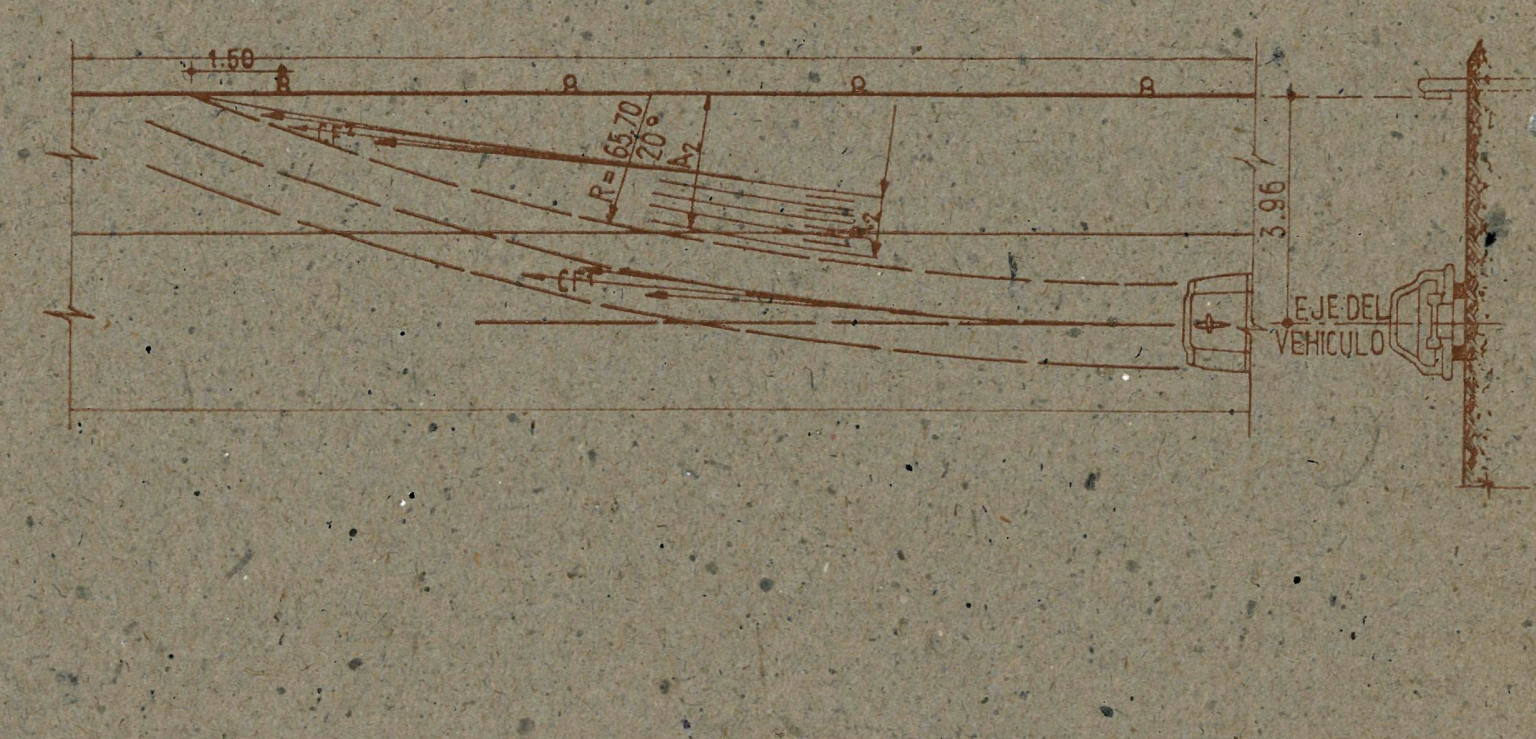

El pretil continuado constituye una especie de valla o barre̊ra de protección, que permite la* tolerancia de grandes velocidades con riesgos menores en lo que respecta a las causas extrañas al propio camino y habilidad del motorista.

El antepecho elástico absorbe durante la deformación momentánea una gran cantidad de la energía del vehículo que choca contra él, pero siempre queda un remanente que tiende a lanzar al vehículo en sentido contrario al del choque. Para contrarrestar esta acción secundaria, los postes que siryen de apoyo a los cables que constituyen el pretil tienen una forma y disposición queg pueden, por sí solos, dísipar una gran parte de la energía del impacto.

Como el número de cables utilizados en la construcción de estos antepechos varía de tres a. seis, dejan suficiente espacio libre para evitar acumulaciones de nievé o agua en casos de nevadas o lluvias.

Los materiales utilizados en estos, pretiles elásticos se protegen convenientemente contra la corrosión y efećtos destructivós que la intemperie pudiera ocasionar, y presentan, por su forma y disposición, un bonito aspecto que da cierta gracia al camino.

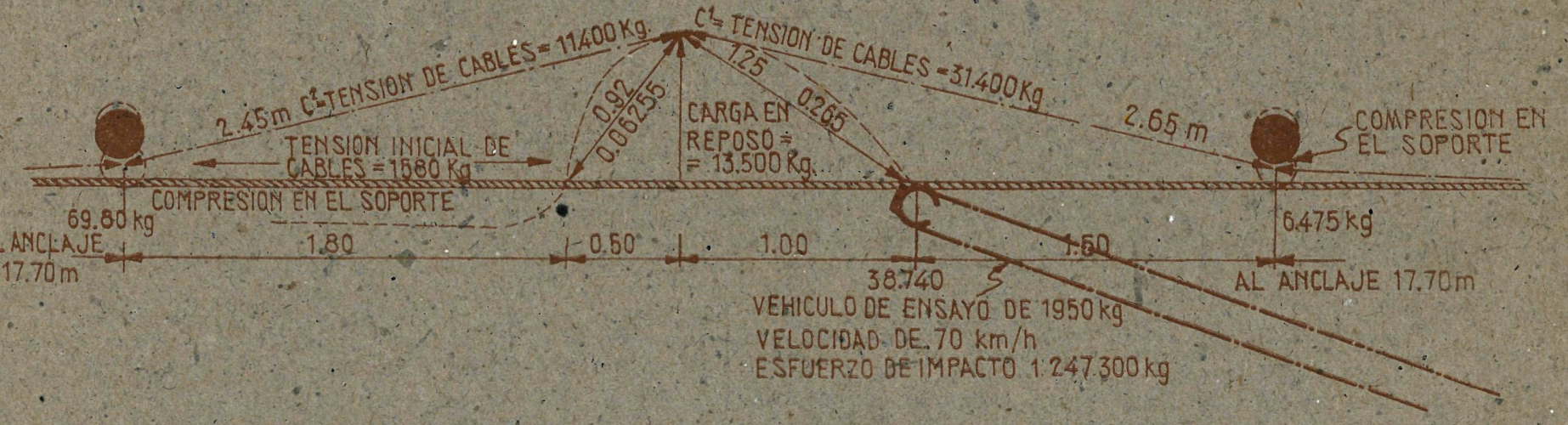

detalle de ensayo 


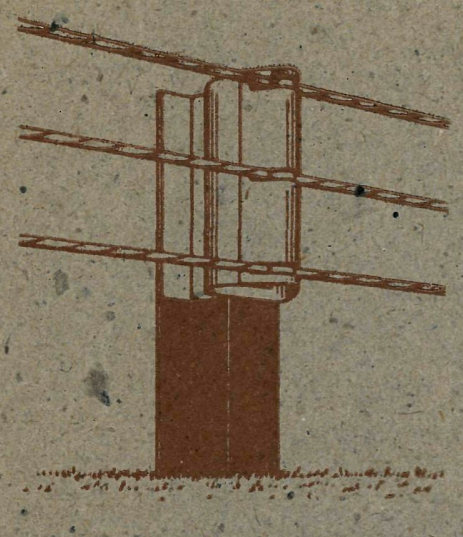

\section{tipos de soportes}

La visibilidad nocturna no es malà, mejorándose notablemente con la que presentan los soportès espaciados a unos $4,80 \mathrm{~m}$, y que se pintan con un color aproplado a la luz diuma y la artificial de los reflectores de los vehículos durante la noche.

\section{Antepecho elástico}

El pretil elástico consiste, en esencia, de una serie de soportes, metálicos, de perfil en forma de doble $T$, espaciados generalmente a menos de $5 \mathrm{~m}$, sobre los que se montan unas pinzas huecas, también metálicas, provistas de unas entallas para la colđcación de los cables que constituyen el antepecho propiamente dicho. Cada una de estas piezas huecas soporta un paquete de tres o cuatro cables: así, pues, si el pretil tiene nueve cables, una de éstas piezas soporta tres cables; y si el antepecho es de sólo tres cables, bastará con una sola pieza.

El número de cables del pretil varía según los casos y circunstancias, pero como medida general varía de tres en los casos más ligeros, a ocho cuando se desea una gran seguridad y vallado.

Los cables, galvanizados, se unen entre sí porimedio de manguitos especiales. Para ponerlos en tensión algunos de los soportes se anclan conyenientemente. La tensión y anclajes no constituye ninguna dificultad.

\section{Ensayos}

- Con objeto de conocer detalladamente el proceso de fuerzas y deformaciones durante el choque del vehículo contra el pretil, se han practicado una serie de ensayos con vehículos de diferente peso y yelocidad.

Del resultado de estos ensayos, ejecutados con gran escrüpulo y meticulosidad, se ha demostrado que esta clase de protecciones presentan condiciones inmejorables para cumplir su finalliad.

J. J. U. 